\title{
New Onset Clitoromegaly in a Preterm Infant: Premature Ovarian Hyperstimulation Syndrome
}

\author{
Rebecca Geliebter, MD, Kristina Derrick MD, Sc M, Beth Drzewiecki, MD, Sarah Rogal, MD, MPH, Jessica \\ Kurian, MD, Jeffrey Gershel, MD, Yogangi Malhotra*, MD \\ NYC Health + Hospitals/Jacobi, Bronx, NY, United States
}

\begin{abstract}
Neonatal clitoromegaly can result from overproduction of androgens by the fetus, the mother, or the placenta. Premature infants can also appear to have clitoromegaly due to variations in external genitalia. The patient reported is an extremely preterm infant who was assigned female sex at birth with a normal physical exam other than premature features. At 35 weeks corrected gestational age (CGA), the patient developed significant clitoromegaly with elevated gonadotropins, androstenedione, and dehydroepiandrosterone sulfate (DHEA-S). Further workup yielded the diagnosis of Premature Ovarian Hyperstimulation Syndrome (POHS). Hormone levels declined over time and her clitoromegaly resolved without intervention. This case of POHS is the first to document elevated DHEA-S as part of the diagnosis. Elevated DHEA-S has not been previously reported in $\mathrm{POHS}$ and it is likely that it contributed to the clitoromegaly. Recognizing POHS is important as the associated clitoromegaly typically resolves.
\end{abstract}

KEYWORDS: Clitoromegaly; Prematurity; Premature Ovarian Hyperstimulation Syndrome

\section{INTRODUCTION}

Neonatal clitoromegaly can result from overproduction of androgens by the fetus, the mother, or the placenta. Premature infants can also appear to have clitoromegaly due to term-size clitoris, prominent labia minora, and/or underdeveloped labia majora. Multiple reports have noted that these findings resolve over a period of months, without any specific intervention. Some patients have had elevated follicle stimulating hormone (FSH), luteinizing hormone (LH), androgens or the presence of ovarian cysts [1-3]. The present patient was an extremely preterm infant with initially normal appearance of the clitoris followed by clitoral enlargement associated with POHS.

Neonatal clitoromegaly is defined as a clitoris length greater than 9 $\mathrm{mm}$ with most term infants having a clitoris length of 4-6 $\mathrm{mm}$ [4-7]. Clitoromegaly should raise the concern for a disorder of sex development (DSD). In a 46, XX female infant, clitoromegaly is typically associated with exposure to excess androgens. High levels of androgens may be due to

\section{Vol No: 06, Issue: 01}

Received Date: November 11, 2020

Published Date: June 30, 2021

\section{*Corresponding Author}

Yogangi Malhotra

NYC Health + Hospitals/Jacobi, Bronx, NY,

United States

E-mail: malhotry@nychhc.org

Citation: Geliebter R, et al. (2021). New Onset Clitoromegaly in a Preterm Infant: Premature Ovarian Hyperstimulation Syndrome. Mathews J Pediatr. 6(1):25.

Copyright: Malhotra Y, et al. (C) 2021. This is an open-access article distributed under the terms of the Creative Commons Attribution License, which permits unrestricted use, distribution, and reproduction in any medium, provided the original author and source are credited. 
overproduction by the fetus [congenital adrenal hyperplasia $(\mathrm{CAH})]$, the mother (tumor: luteoma, adrenal, ovarian; medication use including progesterone and untreated $\mathrm{CAH}$ ), or the placenta (aromatase deficiency and P450 oxidoreductase deficiency) [8]. The possibility of 46, XY DSD with significant under virilization is also in the differential. It is important to determine the cause of clitoromegaly to avoid a CAH-related salt-wasting crisis, to ensure appropriate sex assignment, and to screen for dysgenic gonads that may develop into a gonadoblastoma [8].

\section{CASE REPORT}

The female patient was born at 25 weeks and 1 day, at a weight appropriate for gestational age; $665 \mathrm{~g}$ (40\%ile on Fenton growth curve). Mother was a 30-year-old G5P3111 with a past medical history of obesity and Herpes Simplex Virus type 2 (HSV-2) infection. She was not started on treatment for HSV-2 as she remained asymptomatic during this pregnancy. She also denied any prodromal symptoms associated with herpes or any signs of virilization during pregnancy. There was preterm premature rupture of membranes at 25 weeks and 1-day gestation, and the delivery was complicated by placental abruption and chorioamnionitis. The mother received a full course of antenatal corticosteroids prior to delivery.

The newborn's physical examination was significant for normal tone, a soft, open, flat fontanel, normal eyes and ears for gestational age, intact palate, no midface hypoplasia, mild respiratory distress, no murmurs, no abdominal masses, a 3-vessel umbilical cord, an intact spine, and normal extremities. The patient was assigned female sex at birth based on her physical exam; clitoral enlargement was not documented at that time. Her initial NICU course was significant for 1) mild respiratory distress syndrome, treated with nasal CPAP, oxygen, and caffeine, 2) transient renal insufficiency likely associated with prematurity, and 3) patent ductus arteriosus that resolved without intervention. There were no episodes of hyper- or hypotension and no hypoglycemia documented after the second day of life. She then remained in the NICU for routine prematurity care, including feeding support. At 35 weeks CGA, both the mother and the neonatology team noted the clitoris was becoming more prominent. The clitoris continued to enlarge to 10 $\mathrm{mm}$ in length and approximately $8 \mathrm{~mm}$ in width, with the posterior labia fused. The labia majora were not rugated or hyperpigmented, and no masses were palpated in the inguinal region. The remainder of the physical examination was mostly unchanged and normal as expected at 35 weeks gestation age. The skin was keratinized and without rashes, the pupils were equal, round and reactive to light, breathing was normal without respiratory distress, heart had a normal rate and rhythm without murmurs, abdomen was soft, nondistended, non-tender and without organomegaly, and there were no other obvious dysmorphic features (Figure 1).

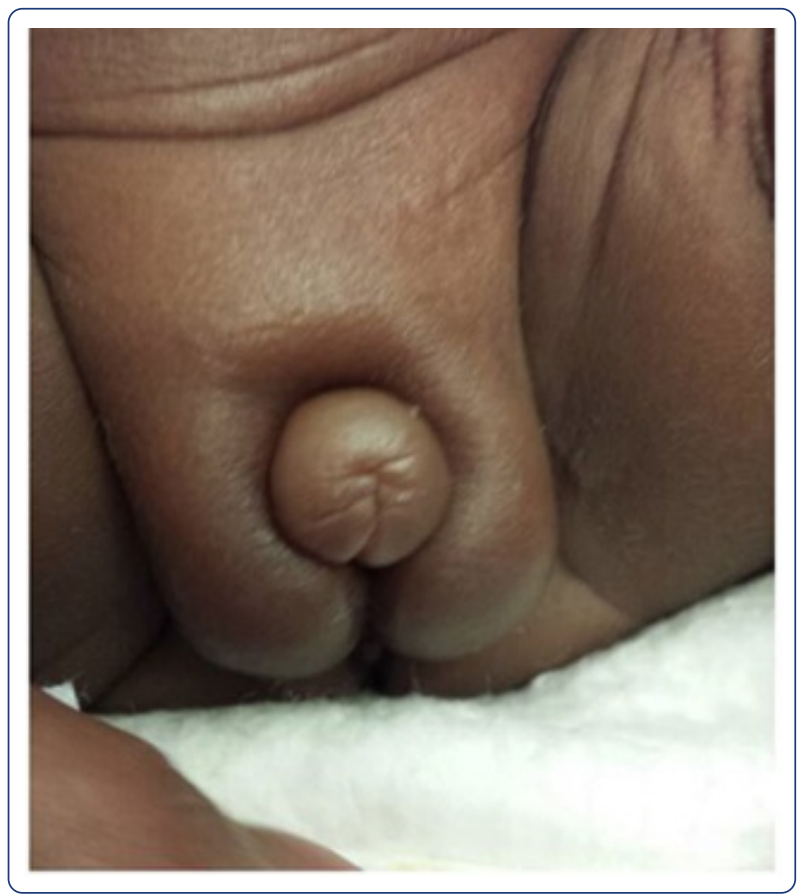

Figure 1: 35 weeks CGA (clitoral size: $10 \mathrm{~mm}$ x $8 \mathrm{~mm}$ ).

At 35 weeks 2 days CGA, a pelvic ultrasound was performed which identified a normal uterus with endometrial stripe at $1 \mathrm{~mm}$ (normal $<1 \mathrm{~mm}$ ), and no ovaries were visualized. Due to an abnormal result seen on a routine newborn screen, a 17-hydroxyprogesterone (17-OHP) level was obtained and found to be elevated to $700 \mathrm{ng} / \mathrm{dL}$ at 30 weeks and 6 days CGA [9]. This was repeated at 34 weeks 3 days CGA and was $294 \mathrm{ng} / \mathrm{dL}$, consistent with a downtrend. At 35 weeks 6 days CGA the gonadotropins were markedly elevated (FSH $120 \mathrm{mIU} / \mathrm{mL}$; LH $49 \mathrm{mIU} / \mathrm{mL}$ ), while both the estradiol (21 pg/mL) and testosterone $(<1 \mathrm{ng} / \mathrm{dL})$ were low [10]. Androstenedione was $95 \mathrm{ng} / \mathrm{dL}$ (reference range, 1-11 month old term infant $=6-78 \mathrm{ng} / \mathrm{dL}$ ), DHEA-S was $293 \mathrm{mcg} /$ $\mathrm{dL}$ (reference range, day of life 4 , premature infant $=122$ $710 \mathrm{mcg} / \mathrm{dL}$, and day of life 3 , full term infant $=88-356 \mathrm{mcg} /$ $\mathrm{dL}$, with normal downtrend to $<112$ during first month of life). Cytogenetic analysis revealed a 46, XX karyotype (30 cells counted).

At 39 weeks CGA, a high dose (125 mcg) cosyntropin stimulation test was performed to evaluate for a rare form of adrenal insufficiency after a repeat DHEA-S notably rose to $849 \mathrm{mcg}$. The DHEA-S was confirmed to be elevated by the Quest Nichols Laboratory at $692 \mathrm{mcg} / \mathrm{dL}$.

The cosyntropin stimulation test results were as shown in table 1. 


\begin{tabular}{|c|c|c|c|}
\hline & Time $=0$ & Time $=1$ hour & Baseline \\
\hline ACTH $(\mathrm{pg} / \mathrm{mL})$ & Quantity not Sufficient & & \\
\hline Cortisol (mcg/dL) & 1.4 & 19.8 & 18.4 \\
\hline Pregnenolone (ng/dL) & 254 & 729 & 475 \\
\hline 17-0H Pregnenolone (ng/dL) & 631 & 3173 & 2542 \\
\hline 11-Deoxycortisol (ng/dL) & 59 & $<15$ & \\
\hline 17-0H Progesterone (ng/dL) & 91 & 126 & 35 \\
\hline Cortisone $(\mathrm{mcg} / \mathrm{dL})$ & 1.78 & 4.79 & \\
\hline DHEA (ng/dL) & $<92$ & 2798 & $2706-2798$ \\
\hline DHEA-S (mcg/dL) & 849 & & \\
\hline Androstenedione (ng/dL) & 38 & 128 & 90 \\
\hline Testosterone (ng/dL) & $<20$ & $<10$ & \\
\hline Corticosterone (ng/dL) & $<34$ & 6238 & \\
\hline 18- Hydroxycorticosterone (ng/dL) & 62 & 1036 & \\
\hline
\end{tabular}

Table 1: Cosyntropin (ACTH) Stimulation test results at 39+0 CGA [11-13].

A repeat pelvic ultrasound revealed bilateral ovaries with multiple follicles, a normal appearing uterus, adrenal glands, and genitourinary tract. The right ovary measured $1.1 \times 0.5$ x $0.8 \mathrm{~cm}$ with volume $0.44 \mathrm{ml}$. The left ovary measured 1.1 x 0.9 x $1.4 \mathrm{~cm}$ with volume $1.39 \mathrm{ml}$. No masses were seen. Repeat gonadotropins at 39 weeks 0 days CGA were notable for FSH of $20 \mathrm{mIU} / \mathrm{mL}$, LH of $0.83 \mathrm{mIU} / \mathrm{mL}$ and anti-mullerian hormone $(\mathrm{AMH})$ of $0.38 \mathrm{ng} / \mathrm{dL}$ (no established reference range for this age, menopause levels are $<0.45 \mathrm{ng} / \mathrm{mL}$ ) [13] (Table 2).

\begin{tabular}{|c|c|c|c|c|c|c|}
\hline CGA & 30wk 6d & 34wk 3d & 35wk 6d & 39wk 0d & 44wk 3d & 50wk 0d \\
\hline LH & & & $49 \mathrm{mIU} / \mathrm{mL}$ & $0.83 \mathrm{mIU} / \mathrm{mL}$ & $2.5 \mathrm{mIU} / \mathrm{mL}$ \\
\hline FSH & & $120.8 \mathrm{mIU} / \mathrm{mL}$ & $20 \mathrm{mIU} / \mathrm{mL}$ & \\
\hline Estradiol & & & $20 \mathrm{pg} / \mathrm{mL}$ & & $706 \mathrm{ug} / \mathrm{dL}$ & $230 \mathrm{ug} / \mathrm{dL}$ \\
\hline DHEA-sulfate & & & $293 \mathrm{ug} / \mathrm{dL}$ & $849 \mathrm{ug} / \mathrm{dL}$ & \\
\hline $\mathbf{1 7 - 0 H P}$ & $719 \mathrm{ng} / \mathrm{dL}$ & $294 \mathrm{ng} / \mathrm{dL}$ & & $91 \mathrm{ng} / \mathrm{dL}$ & \\
\hline
\end{tabular}

Table 2: Hypothalamic-Pituitary-Gonadal and Hypothalamic-Pituitary-Adrenal Axis Testing by CGA. 
At CGA 44 weeks and 3 days (4 months chronological age), the repeat DHEA-S was $706 \mathrm{mcg} / \mathrm{dL}$. A follow-up examination at 50 weeks and 0-day CGA (6 months of age) showed complete resolution of the clitoromegaly, normal appearing, clearly separated labia without rugae or hyperpigmentation (Figure 2A, 2B). Repeat laboratory testing at that time showed normalization of DHEA-S (230 mcg/dL), and FSH (2.5 mIU/mL).

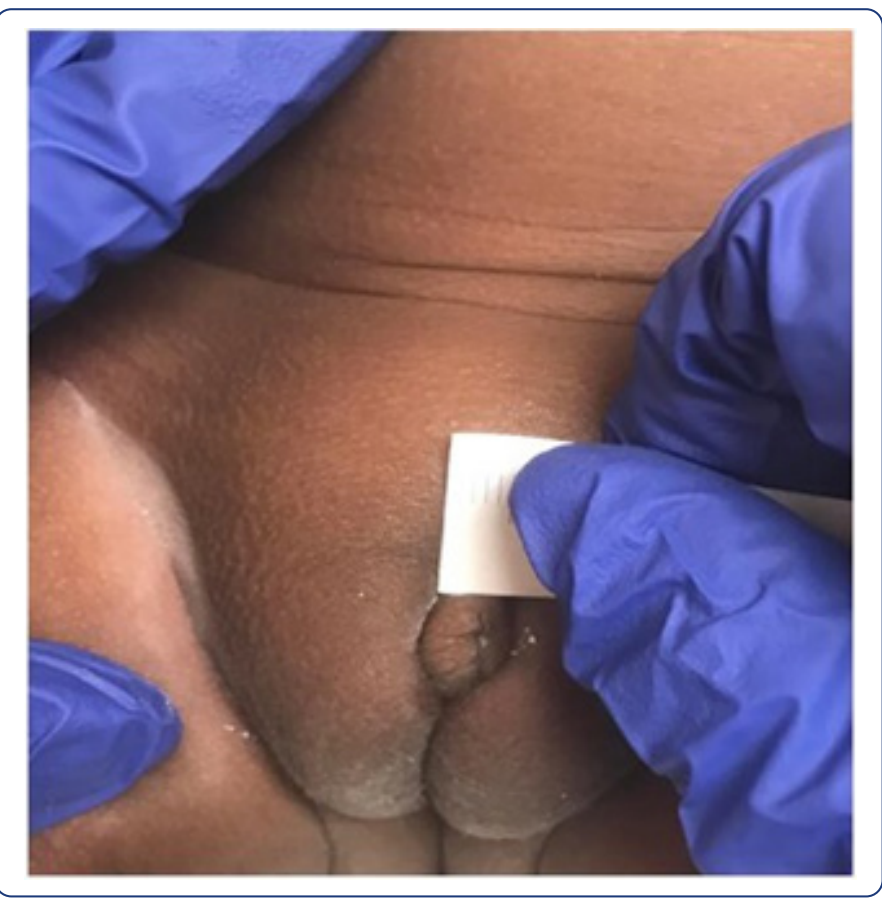

A)

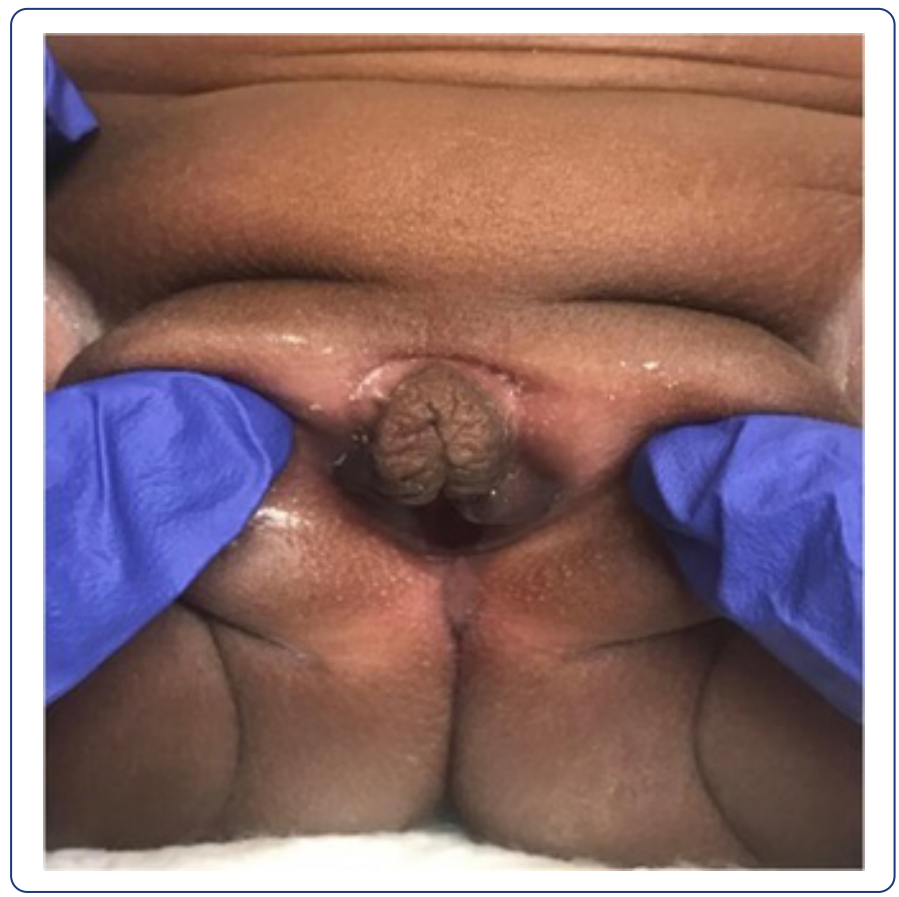

B)

Figure 2A \& B: 2 images at 50 weeks CGA (clitoral size 8mm x $5 \mathrm{~mm})$.

\section{DISCUSSION}

The patient's clinical course and changes in gonadotropins was most consistent with premature ovarian hyperstimulation syndrome. The fetal adrenal gland is known to produce relatively high levels of DHEA and DHEA-S due to lack of 3-beta hydroxysteroid dehydrogenase activity. As premature infants approach term, the levels of DHEA and DHEA-S typically normalize, as was appreciated in our patient's initial DHEA-S. However, the DHEA-S then rose significantly and in the setting of evidence of virilization (enlargement of the clitoris) was concerning for adrenal pathology. The subsequent normalization of DHEA-S, essentially normal cosyntropin stimulation test, and normal adrenal ultrasound support that there was no significant adrenal pathology. To our knowledge, this is the first report of POHS with documentation of a rise in DHEA-S. We hypothesize that a transient excess androgen led to the temporary clitoromegaly, and with normalization of DHEA-S, the clitoromegaly resolved [11].

While few similar cases have been reported, the mechanisms behind the physical changes demonstrate the potential for many more patients to have a similar issue [12]. In addition, we believe the rise and resolution in DHEA-S has not been previously reported in the documentation of POHS. This patient's spontaneous resolution of abnormal physical findings is reassuring. However, it remains unclear whether POHS may pose future risk of ovarian conditions such as polycystic ovary syndrome or infertility. The physicians examining such children will typically include general pediatricians, potentially on the first post-discharge visit, and neonatologists, before discharge from the hospital [1316]. Thus, it is important for newborn caregivers to be aware of the phenomenon of premature ovarian hyperstimulation syndrome.

\section{ACKNOWLEDGEMENT}

We would like to thank Dr. Molly Regelman for her guidance in the clinical care, the diagnostic workup and the review of our manuscript.

\section{BIBLIOGRAPHY}

1. Nerre AL, Betremieux P, Nivot-Adamiak S. (2017). Case Report of Clitoral Hypertrophy in 2 Extremely Premature Girls With an Ovarian Cyst. Pediatrics. 140(4) e20161807.

2. Greaves R, Kanumakala S, Read A, Zacharin M. (2004). Genital abnormalities mimicking congenital adrenal hyperplasia in premature infants. J Paediatr Child 
Health. 40(4):233-6.

3. Dumont T, Black AY, Ahmet A, Fleming NA. (2009). Isolated transient neonatal clitoromegaly with hyperandrogenism of unknown etiology. J Pediatr Adol Gynecol. 22(5):e142-5.

4. Oberfield SE, Mondok A, Shahrivar F, Klein JF, Levine LS. (1989). Clitoral size in full term infants. Am J Perinatol. 6(4):453-4.

5. Phillip M, De Boer C, Pilpel D, Karplus M, Sofer S. (1996). Clitoral and penile sizes of full term newborns in two different ethnic groups. J Pediatr Endocrinol Metab. 9(2):175-9.

6. Riley WJ, Rosenbloom AL. (1980). Clitoral size in infancy. J Pediatr. 96(5):918-9.

7. Brodie KE, Grantham EC, Huguelet PS, Caldwell BT, Westfall NJ, et al. (2016). Study of clitoral hood anatomy in the pediatric population. J Pediatr Urol. 12(3):177. e171-175.

8. Lee PA, Houk CP, Ahmed SF, Hughes IA. (2006). Consensus statement on management of intersex disorders. International Consensus Conference on Intersex. Pediatrics. 118(2):e488-500.

9. Speiser PW, Azziz R, Baskin LS, Baskin LS, Conway GS, et al. (2010). Congenital adrenal hyperplasia due to steroid 21-hydroxylase deficiency: An Endocrine Society clinical practice guideline. J Clin Endocrinol Metab. 95(9):41334160.

10. Rebar RW, Erickson GF, Yen SS. (1982). Idiopathic premature ovarian failure: clinical and endocrine characteristics. Fertil Steril. 37(1):35-41.
11. Johannsen TH, Main KM, Ljubicic ML, Jensen TK, Andersen HR, et al. (2018). Sex Differences in Reproductive Hormones During Mini-Puberty in Infants With Normal and Disordered Sex Development. J Clin Endocrinol Metab. 103(8):3028-3037.

12. Greaves RF, Pitkin J, Ho CS, Baglin J, Hunt RW, et al. (2015). Hormone modeling in preterm neonates: establishment of pituitary and steroid hormone reference intervals. J Clin Endocrinol Metab. 100(3):1097-1103.

13. Lee MM, Misra M, Donahoe PK, MacLaughlin DT. (2003). MIS/AMH in the assessment of cryptorchidism and intersex conditions. Mol Cell Endocrinol. 211(1-2):91-8.

14. Kuiri-Hanninen T, Haanpaa M, Turpeinen U, Hämäläinen E, Seuri R, et al. (2013). Postnatal ovarian activation has effects in estrogen target tissues in infant girls. J Clin Endocrinol Metab. 98(12):4709-16.

15. Bergada I, Milani C, Bedecarras P, Andreone L, Ropelato MG, et al. (2006). Time course of the serum gonadotropin surge, inhibins, and anti-Mullerian hormone in normal newborn males during the first month of life. J Clin Endocrinol Metab. 91(10):4092-8.

16. Couch R, Girgis R. (2012). Postnatal virilization mimicking 21-hydroxylase deficiency in 3 very premature infants. Pediatrics. 129(5):e1364-7. 